\title{
Effect of Tinnitus Habituation Therapy on Auditory Abilities
}

\author{
Najlla Lopes de O. Burle ${ }^{10}$ Luciana Macedo de Resende ${ }^{20}$ Luciana Mendonça Alves ${ }^{20}$ \\ Vinícius Soares Garcia1 Patricia Cotta Mancini ${ }^{2}{ }^{10}$
}

1 Post-Graduate Program in Speech Therapy Sciences, Universidade Federal de Minas Gerais, Belo Horizonte, MG, Brazil

Address for correspondence Patrícia Cotta Mancini, PhD,

2 Department of Speech-Language Pathology and Audiology, Universidade Federal de Minas Gerais, Belo Horizonte, MG, Brazil Departmento de Fonoaudiologia, Universidade Federal de Minas Gerais, Avenida Alfredo Balena, 190, Santa Efigênia, Belo Horizonte, Minas Gerais, Brazil (e-mail: patmancini@gmail.com).

Int Arch Otorhinolaryngol 2021;25(1):e18-e26.

\begin{abstract}
Keywords

- tinnitus

- auditory abilities

- auditory perception
\end{abstract}

\section{Introduction}

Tinnitus is the perception of a sound in the ears or in the head, in the absence of an external stimulus. ${ }^{1}$ It is a symptom that can reflect on the functioning of the organism of an individual as a whole, and can be caused by numerous affections including otological, metabolic, neurological, orthopedic, cardiovascular, pharmacological, odontological, and/or psychological, which, in turn, may be present concomitantly in the same individual., ${ }^{2,3}$

received

July 17,2019

accepted

January 13, 2020

published online

April 24, 2020
DOI https://doi.org/ 10.1055/s-0040-1708897. ISSN 1809-9777.
Tinnitus consists of a symptom that is present in $15 \%$ of the general population, and its incidence increases to $33 \%$ in the elderly. ${ }^{4}$ Approximately $40 \%$ of tinnitus patients also suffer from hyperacusis, which consists of a decreased tolerance to sounds at intensities considered comfortable to most people. ${ }^{5}$ In many cases, tinnitus may cause a great deal of discomfort. Given its difficulty in characterization and treatment, and according to its severity, tinnitus becomes a negative repercussion factor in the life of the individual, hampering their

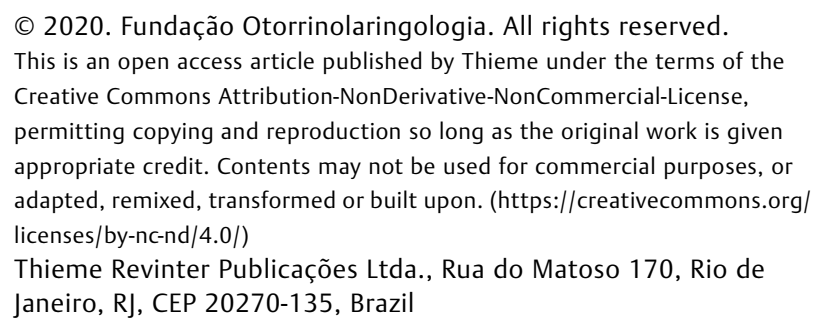


sleep, concentration, daily and professional activities, social life and, often, altering their emotional balance. ${ }^{6}$

Tinnitus may occur in patients with normal hearing or who exhibit hearing loss. ${ }^{7}$ Even with normal hearing thresholds, almost half of the individuals affected by tinnitus complain of reduced ability to communicate and discriminate words. ${ }^{8}$ Studies with patients with hearing loss ${ }^{9}$ and with patients with normal hearing ${ }^{10,11}$ have verified that tinnitus interferes in auditory processing and speech perception in a noisy environment for some hearing abilities, regardless of the contextual clues that are provided during the dialogue, therefore affecting the communication of the individual. Communication losses due to tinnitus can make people irritated, anxious, distressed, depressed, and insomniac, hampering their quality of life. ${ }^{12,13}$

Due to its complex, multiple, and not yet well-understood pathophysiology, several therapeutic modalities have been employed in the attempt to cure or even relieve and reduce the perception of tinnitus and hyperacusis. One of the strategies consists of tinnitus habituation therapy, ${ }^{14} \mathrm{a}$ treatment based on the neurophysiological model of tinnitus, described by Jastreboff in $1990 .{ }^{15}$ In this model, the disorder is considered the result of a dynamic interaction between some centers of the central nervous system, including auditory and nonauditory pathways. One of these interactions occurs between the limbic and the autonomic nervous systems, generating negative sensations, such as nuisance and stress, which inhibit the habituation of this symptom. ${ }^{16}$ Habituation is defined as a physiological process characterized by the progressive decline of responses to repetitive stimuli and only occurs if the stimulus is neutral, that is, free from associations with negative emotional states. ${ }^{17}$

In order for the complete process of tinnitus habituation to occur, two fundamental principles should be equally valued: counseling and sound therapy. ${ }^{18}$ The objective of counseling is to remove adverse associations of tinnitus and demystify negative beliefs related to the symptom. ${ }^{17}$ It consists of an explanation of the anatomy and physiology of central and peripheral hearing, and its relationship with tinnitus, in addition to recommendations. In turn, sound therapy aims at facilitating the habituation of tinnitus perception for symptom relief by reducing the difference between tinnitus-related and background neuronal activity. ${ }^{18}$ The habituation-based treatment of tinnitus produces changes in the neural connections of the auditory system and may require some time to take place. Some patients become accustomed quickly, although, by definition, the complete process can occur in up to 18 months. ${ }^{18}$ The benefits of this method of treatment for tinnitus are welldescribed in the literature, and several studies have highlighted the reduction of tinnitus loudness in patients with this symptom, as well as the reduction of the impact of tinnitus on the quality of life of the patients. ${ }^{15,18,19}$

Nevertheless, although the efficacy of tinnitus habituation therapy and the possible influence of this symptom on auditory processing skills are well-understood, studies that assess whether or not tinnitus improvement through this form of treatment influences auditory processing are not yet explored. Thus, the objective of the present study was to verify the effect of tinnitus habituation therapy on the auditory skills, assessed through behavioral auditory processing tests, self-perception of tinnitus in relation to loudness, discomfort, and the impact of tinnitus on the quality of life of individuals with this symptom.

\section{Methods}

The present research comprised a quasi-experimental study that was conducted at a Research Laboratory at Federal University of Minas Gerais, in the city of Belo Horizonte, Brazil. The study was previously approved by the Ethics and Research Committee under the number 48473215.9.0000.5149. The participants were referred to the Research Laboratory by the Auditory Health Care Service. All of the individuals presented with tinnitus and were evaluated by an otorhinolaryngologist, who referred the patients to the Vestibular Rehabilitation and Tinnitus Ambulatory of the university hospital in order to carry out tinnitus habituation therapy.

The inclusion criteria comprised individuals $>18$ years old with tinnitus causing an impact on their quality of life, and who were referred by an otorhinolaryngologist for tinnitus habituation therapy. The exclusion criteria included patients with significant hearing loss ( $>50 \mathrm{dBHL}$ ), given this characteristic hampered the behavioral assessment of auditory processing since the use of hearing aids (HAs) in these individuals was necessary; patients who already used HAs; patients who exhibited significant emotional or cognitive conditions (generalized anxiety, panic disorder, dementia, self-reported or evident depression, or schizophrenia); participants that presented type As, B, C or Ad tympanometric curves, which encumber the performance of auditory processing evaluations, and individuals who did not seem uncomfortable with tinnitus. The subjects who agreed to participate in the study were required to sign an informed consent term (ICT).

A total of 41 patients were included in the study, of which 3 dropped out of the treatment, 4 chose not to continue, 1 exhibited an Ad-type tympanometric curve and 1 had a type C tympanometric curve, 5 displayed self-reported emotional or cognitive disturbances, 5 already used HAs, 2 did not report discomfort with tinnitus, and 1 had severe hearing loss, and were, therefore, excluded from the study. Thus, the final sample consisted of 19 individuals.

Initially, all of the subjects were asked to attend an initial counseling group session, and they were explained the pathophysiology of tinnitus and the objectives of the research. At this stage, the patients were invited to participate in the study, and those who agreed signed the ICT. The tests were scheduled and performed at the research laboratory facility.

All of the patients were initially submitted to anamnesis, tinnitus handicap inventory (THI) questionnaire, visual analog scale (VAS), otoscopy, and audiological, tinnitus, and auditory processing evaluations. These procedures were divided into two sessions, each lasting $\sim 1$ hour, to avoid fatigue, drowsiness, and discomfort of the participant. 
In the anamnesis, the participants were asked about tinnitus issues such as tinnitus type, location, associated pains, eating habits, current comorbidities, medications in use and already used for the symptom, and family history of tinnitus, hearing loss, and diabetes.

The THI questionnaire was applied to verify the impact of tinnitus on the quality of life of the individuals. It comprises 25 questions that assess the functional, emotional and catastrophic aspects of tinnitus. The patient should answer the questions with "yes," "sometimes," and "no," which scored four, two, and zero points, respectively. Thus, the maximum score in this questionnaire was 100 , and the higher the score, the greater the impact of tinnitus on the individual's quality of life.

The visual analog scale (VAS) was used to verify the degree of annoyance of the patient because of tinnitus. The individuals were instructed to visualize the scale and then assign a score from 0 to 10 regarding the annoyance generated by tinnitus, 10 being unbearable, and 0 meaning no nuisance brought on by tinnitus.

Meatoscopy was performed to verify if the conditions of the external auditory meatus were adequate to carry out the hearing tests. The audiological evaluation was conducted in an acoustically treated environment, according to ISO 8253$120,{ }^{20}$ using the model Astera 2 Otometrics audiometer (Natus, Taastrup, Denmark), the Sennheiser HDA 200 headset (Sennheiser, Wedemark, Germany), and the B-71 bone vibrator (RadioEar, Middelfart, Denmark). The exam consisted of conventional and high-frequency audiometry, with air (frequencies from 250 to $20,000 \mathrm{~Hz}$ ) and bone auditory thresholds (frequencies between 500 and $4,000 \mathrm{~Hz}$ ), and speech audiometry using recorded material (speech recognition threshold [SRT] and the speech recognition index [SRI]). The audiometric classification followed the criteria proposed by Biap ${ }^{22}$ which considers the average air thresholds at frequencies of 500,1,000,2,000, and 4,000 Hz.

Immitance measures consisted of tympanometry and contralateral acoustic reflexes at frequencies of 500, 1,000, 2,000 , and $4,000 \mathrm{~Hz}$. The tests were performed on the Interacoustics immitanciometer, model AT235 (Interacoustics, Middelfart, Denmark), and the tympanometry classification followed the criteria proposed by Jerger. ${ }^{22}$ The purpose of this stage was to evaluate the functional integrity of middle ear structures, since alterations in these structures may influence the auditory processing evaluation results.

The tinnitus assessment was composed of acuphenometry and the loudness discomfort levels (LDLs). Acuphenometry consists of a subjective evaluation performed using an audiometer, in which the participant is subject to several sound stimuli in order for comparison with the tinnitus reported by the patient, thus characterizing the symptom regarding its pitch and loudness. To evaluate the frequency, pure tones or narrowband noises were presented, depending on the characterization reported by the patient, at frequencies of $250 \mathrm{~Hz}$ to $20,000 \mathrm{~Hz}, 10.0 \mathrm{dBHL}$ above the audiometric threshold. In turn, to measure the loudness sensation, the signal was increased in steps of $1 \mathrm{~dB}$ on the determined frequency, and patients were instructed to raise their hand when the signal was at an equivalent loudness to that of the tinnitus. This evaluation
Table 1 Hyperacusis classification according to Goldstein et $\mathrm{al}^{23}$

\begin{tabular}{|l|l|}
\hline Hyperacusis & Discomfort Threshold \\
\hline Negative & $95 \mathrm{db}$ or $>$ at all frequencies \\
\hline Mild & $80-90 \mathrm{db}$ at two or more frequencies \\
\hline Moderate & $65-75$ at two or more frequencies \\
\hline Severe & $60 \mathrm{db}$ or $<$ at two or more frequencies \\
\hline
\end{tabular}

was performed in the contralateral ear to the one exhibiting tinnitus, or in the ear in which the patient reported the least annoyance. $^{22}$ The LDLs were determined at frequencies of 500 to $4,000 \mathrm{~Hz}$ using pure tones, and the intensity of stimulus presentation was increased in steps of $1 \mathrm{~dB}$. Patients were instructed to raise their hands when they felt discomfort in relation to the sound. The hyperacusis classification was in accordance with the criteria proposed by Goldstein et $\mathrm{al}^{23}$ and is described in $\mathbf{- T a b l e ~} \mathbf{1}$.

To perform the behavioral evaluation of auditory processing, tests were chosen to assess each auditory ability. Therefore, a low-redundancy monoaural speech test (noisy speech [NS]), dichotic hearing test (staggered spondaic word test [SSW]), temporal processing tests (pitch pattern sequence [PPS] and gaps in noise [GIN]), and a binaural interaction test (masking level difference [MLD]) were performed. The behavioral tests were also performed in an acoustic booth, using the Itera II Otometrics two-channel audiometer (Natus, Taastrup, Denmark), coupled with a media player and TDH-39 headphones (Telephonics, Farmingdale, United States). - Table 2 shows the tests that were employed in the behavioral evaluation

Table 2 Auditory processing tests, evaluated abilities, and performance parameters

\begin{tabular}{|l|l|l|}
\hline Test & Hearing Abilities & Performance Parameters \\
\hline NS & Auditory Closing & $\begin{array}{l}\text { Monoaural presentation at } \\
\text { 40 dBSL of 25 monosyllables } \\
\text { with ipsilateral white noise } \\
\text { at a S/R ratio }=+5\end{array}$ \\
\hline SSW & $\begin{array}{l}\text { Figure-background } \\
\text { for verbal sounds } \\
\text { Binaural integration } \\
\text { Binaural separation }\end{array}$ & $\begin{array}{l}\text { Dichotic presentation at } \\
50 \mathrm{dBSL} \text { of four alternate } \\
\text { disyllables. }\end{array}$ \\
\hline PPS & Temporal ordination & $\begin{array}{l}\text { Monoaural presentation at } \\
50 \mathrm{dBSL} \text { of three pure tones } \\
\text { in sequence for the patient } \\
\text { to designate as delicate/ } \\
\text { heavy (sharp/bass). }\end{array}$ \\
\hline GIN & Temporal resolution & $\begin{array}{l}\text { Monoaural presentation at } \\
50 \mathrm{dBSL} \text { for the detection of } \\
\text { silence intervals in the noise. }\end{array}$ \\
\hline MLD & Binaural interaction & $\begin{array}{l}\text { Binaural presentation at } \\
50 \mathrm{dBSL} \text { of noise and } \\
\text { pulsatile tones of 500 Hz, } \\
\text { in and out of phase. }\end{array}$ \\
\hline
\end{tabular}

Abbreviations: dBSL, sensation level decibels; GIN, gap in noise; $\mathrm{Hz}$, hertz; MLD, masking level difference; NS, noisy speech; PPS, pitch pattern sequence; S/R, signal/noise ratio; SSW, staggered spondaic word test. 
of auditory processing, as well as the assessed hearing abilities in each one, in addition to the applied performance parameters.

After completion of the test, the patients were invited to attend a second lecture aimed at guiding them regarding the lifestyle changes that can help reducing the discomfort of tinnitus, as well as to explain about tinnitus habituation therapy and its possible benefits. After the talk, the patients received an MP3 player containing songs of environmental and instrumental sounds to provide sound therapy, were guided on the use and handling of the device, and told to use it for at least 3 hours daily, at the moment in which the tinnitus annoyed them most. In addition, patients received a control chart to follow the time of daily use of the MP3 player. They were instructed to mark an " $\mathrm{X}$ " in the square corresponding to the daily use period of the device, in which the options were "up to 1 hour," " 1 to 3 hours," and "more than 3 hours."

Then, the patients underwent tinnitus therapy for a period of 6 months, and 3 appointments were conducted during this time. The $1^{\text {st }}$ and $2^{\text {nd }}$ meetings were performed in the $1^{\text {st }}$ and $3^{\text {rd }}$ months of therapy, respectively, and aimed at reestablishing the given guidelines, motivating the patient to keep the treatment, and to follow-up on their evolution and clarify concerns or misconceptions. The third meeting was performed at the end of the $6^{\text {th }}$ month of therapy, in which the patients were again submitted to acuphenometry, LDLs, all of the behavioral auditory processing tests, and THI and VAS.

All of the data were recorded in specific forms and later released in Excel 2013 (Microsoft Corporation, Redmond, WA, USA) program worksheets for results analysis. Descriptive statistics and statistical analyses were performed using the Student T, T-Paired, and Wilcoxon tests for numerical variables, and the Shapiro-Wilk and chi-squared tests for categorical variables, with a significance level of $5 \%(p<0.05)$ and confidence intervals (CIs) of $95 \%$ in all of the analyses.

\section{Results}

The study sample consisted of 19 individuals, of which 11 were female, and 8 were male. The mean age was 59 years old ( \pm 9.6 ), ranging from 40 to 74 years old. The data regarding the tinnitus characteristics of the participants are shown in -Table 3. In the sample, $57.9 \%$ of the subjects stated that they were uncomfortable with intense sounds, and $42.1 \%$ were not bothered by them. Regarding dizziness, $42.1 \%$ reported the presence of the symptom, while $57.9 \%$ reported it had never occurred.

The individuals were also asked if they had frequent pains, such as otalgia, headaches, neck pain, and in the temporomandibular joint (TMJ). The most frequent pain was headache, reported by $41.2 \%$ of the sample ( - Table 4 ). Regarding eating habits, $73.7 \%$ of the participants reported consuming from 4 to 6 meals per day, and the others stated having 1 to 3 meals a day. A total of $47.4 \%$ stated they ingested high doses of caffeine daily and $57.9 \%$ informed sweet food consumption abuse. As for previous disease history, head trauma, high blood pressure, migraines, cardiac disorders, diabetes, and high cholesterol levels were reported (- Table 5).
Table 3 Data regarding the tinnitus characteristics of the participants

\begin{tabular}{|c|c|c|c|}
\hline \multicolumn{2}{|c|}{ Tinnitus characteristics } & \multirow{2}{*}{$\begin{array}{l}n \\
7\end{array}$} & \multirow{2}{*}{\begin{tabular}{l|}
$\%$ \\
36.8
\end{tabular}} \\
\hline Sound & Cricket & & \\
\hline & Wheezing/Creaking & 7 & 36.8 \\
\hline & Pressure Pot & 2 & 10.5 \\
\hline & Cicada & 1 & 5.3 \\
\hline & Bee & 1 & 5.3 \\
\hline & Drops & 1 & 5.3 \\
\hline \multirow[t]{6}{*}{ Localization } & RE & 4 & 21.1 \\
\hline & LE & 1 & 5.3 \\
\hline & $\mathrm{RE}>\mathrm{LE}$ & 4 & 21.1 \\
\hline & $L E>R E$ & 4 & 21.1 \\
\hline & $\mathrm{RE}=\mathrm{LE}$ & 4 & 21.1 \\
\hline & Head & 2 & 10.5 \\
\hline \multirow{2}{*}{$\begin{array}{l}\text { Duration of } \\
\text { tinnitus }\end{array}$} & Constant & 16 & 84.2 \\
\hline & Variable & 2 & 15.8 \\
\hline \multirow[t]{4}{*}{ Loudness } & Mild & 5 & 26.3 \\
\hline & Moderate & 9 & 47.4 \\
\hline & Intense & 2 & 10.5 \\
\hline & Variable & 3 & 15.8 \\
\hline \multirow[t]{3}{*}{ Occurrence } & Sporadic & 2 & 10.5 \\
\hline & Frequent & 4 & 21.1 \\
\hline & Very frequent & 13 & 68.4 \\
\hline \multirow[t]{2}{*}{ Onset } & Sudden & 9 & 47.4 \\
\hline & Progressive & 10 & 52.6 \\
\hline
\end{tabular}

Abbreviations: \%, percentage; LE, left ear; $n$, number of individuals; RE, right ear.

Table 4 Data regarding the presence of frequent pain in the sample

\begin{tabular}{|l|l|l|}
\hline Frequent pain & N & \% \\
\hline Headache & 8 & 42.1 \\
Neck pain & 5 & 26.3 \\
TMJ & 3 & 15.8 \\
Otalgia & 1 & 5.3 \\
\hline
\end{tabular}

Abbreviations: TMJ, temporomandibular joint; $\mathrm{N}$, number of individuals; $\%$, percentage.

Table 5 Data regarding the past disease history in the sample

\begin{tabular}{|l|l|l|}
\hline Diseases & N & $\%$ \\
\hline High blood pressure & 5 & 26.3 \\
Migraines & 4 & 21.1 \\
Diabetes & 3 & 15.8 \\
Heart disorders & 2 & 10.6 \\
Cranial trauma & 1 & 5.3 \\
High cholesterol & 1 & 5.3 \\
\hline
\end{tabular}

Abbreviations: $\mathrm{N}$, number of individuals; \%, percentage. 


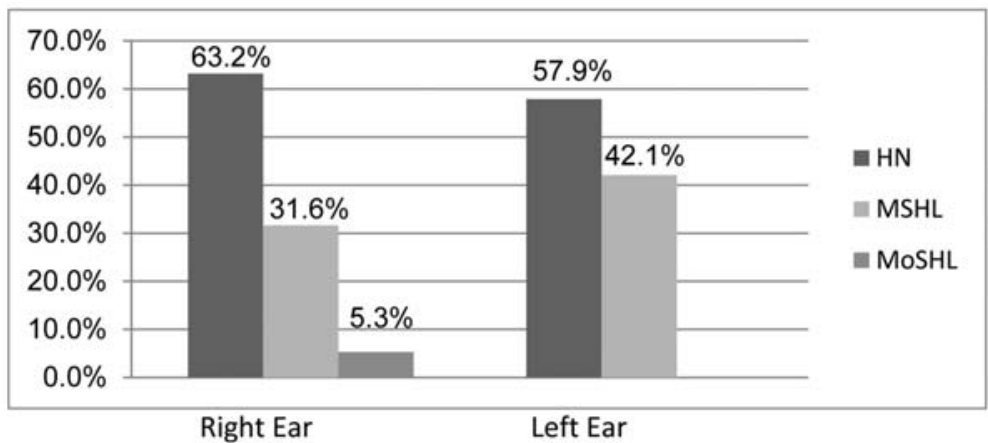

Abbreviations: HN: Hearing within the normality standards; MSHL: Mild sensorineural

hearing loss; MoSHL: Moderate sensorineural hearing loss.

Fig. 1 Auditory classification of the participants. Abbreviations: HN: Hearing within the normality standards; MSHL: Mild sensorineural hearing loss; MoSHL: Moderate sensorineural hearing loss.

Regarding the drugs used during the study, $47.4 \%$ of the patients reported not using any medication, $31.6 \%$ stated using between 1 and 3 substances, and 21.1\% informed the use of $>3$ medications. Specific drugs for tinnitus relief were used prior to the study by $26.3 \%$ of the subjects.

As for the family illness history of the participants, $21.1 \%$ reported having family members with hearing loss, $31.6 \%$ had relatives with tinnitus, and $42.1 \%$ with diabetes. Considering the criteria adopted for auditory loss classification, more than half of the participants exhibited hearing within the normal standards, as observed in - Fig. 1.

Regarding the established exclusion criteria, all of the participants presented a type A tympanogram, according to the classification of Jerger. ${ }^{21}$ Regarding the stapedial reflexes, more than half of the patients (52.6\%) did not exhibit reflexes in both ears.

In acuphenometry, regarding frequency, $78.9 \%$ of the patients reported the presence of tinnitus at high frequencies, such as $6,000 \mathrm{~Hz}$, and only $21.1 \%$ of the subjects stated perceiving tinnitus at low frequencies (250 and $500 \mathrm{~Hz}$ ). This result was maintained after 6 months of therapy, in the reassessment session. Regarding tinnitus loudness, a comparison between pre- and post-treatment values was conducted using the chi-squared test, and a statistically significant difference was observed (-Table $\mathbf{6}$ ).

A Shapiro-Wilk test was also performed to verify the relationship between the initial and final tinnitus loudness in acuphenometry and the amount of medications used by the participants. A statistically significant difference was observed in the group that used 1 to 3 drugs in the final acuphenometry $(p=0.037)$, exhibiting a smaller reduction in tinnitus loudness.

Regarding hearing hypersensitivity, participants were classified based on the values obtained in the LDLs, according to the criteria proposed by Goldstein et al. ${ }^{23}$ Eleven of the 19 participants reported discomfort with intense sounds during anamnesis. Ten exhibited auditory hypersensitivity in the right ear, and twelve in the left ear, determined by LDLs examination.

The comparison between pre- and post-treatment LDLs values in the sample was performed using the chi-squared test, and statistically significant differences were not observed. Data regarding the comparisons between initial and final LDLs are shown in - Table 7. Considering the various tests applied in the pre- and post-treatment evaluations, the results are shown in - Table 8 .

To verify the influence of hearing loss on the auditory processing tests, a comparison was conducted using the results obtained in the patients with and without hearing loss. A statistically significant difference $(p=0.045)$ was observed only in the SSW test in the right competitive condition. The other tests did not show statistical differences between individuals with and without hearing loss.

\section{Discussion}

Regarding gender, $57.9 \%$ of the participants were female and $42.1 \%$ were male, demonstrating an almost equivalent distribution. The literature is controversial concerning the influence of gender on the prevalence of tinnitus. Some studies have

Table 6 Comparisons between the tinnitus loudness values obtained in pre- and post-treatment Acuphenometry

\begin{tabular}{|l|l|l|l|l|l|}
\hline Loudness (dBNS) & Minimum & Maximum & Average & Standard deviation & $p$-value \\
\hline Initial & 1 & 12 & 7.16 & 3.35 & $0.001^{*}$ \\
Final & 1 & 10 & 4.26 & 2.46 & \\
\hline
\end{tabular}

Abbreviations: $\mathrm{N}$, number of individuals; \%, percentage; $p$-value, $p$ significance value (Chi-square test). 
Table 7 Comparisons between the pre- and post-treatment discomfort thresholds, per ear

\begin{tabular}{|l|l|l|l|l|}
\hline \multicolumn{2}{|l|}{ Discomfort Threshold } & N & $\%$ & p-value \\
\hline Initial RE & Negative & 6 & 31.6 & \\
& Mild & 6 & 31.6 & \\
& Moderate & 3 & 15.8 & \\
& Severe & 4 & 21.1 & \multirow{2}{*}{0.416} \\
Final RE & Negative & 9 & 47.4 & \\
& Mild & 6 & 31.6 & \\
& Moderate & 3 & 15.8 & \\
& Severe & 1 & 5.3 & \\
\hline Initial LE & Negative & 7 & 36.8 & \\
& Mild & 5 & 26.3 & \\
& Moderate & 3 & 15.8 & \\
& Severe & 4 & 21.1 & \multirow{2}{*}{0.287} \\
\hline \multirow{2}{*}{ Final LE } & Negative & 11 & 57.9 & \\
& Mild & 2 & 10.5 & \\
& Moderate & 5 & 26.3 & \\
& Severe & 1 & 5.3 & \\
\hline
\end{tabular}

Abbreviations: $\mathrm{N}$, number of individuals; \%, percentage; $p$-value, $p$ significance value (Chi-square test); RE, right ear; LE, left ear.

shown that tinnitus is more prevalent in males, ${ }^{24,25}$ while others suggest a predominance in females ${ }^{26,27}$. One possible reason for the higher prevalence in males would be the fact that they are more present in occupational environments with high levels of noise, and, therefore, are more predisposed to hearing loss and tinnitus. ${ }^{28}$ On the other hand, the more considerable occurrence in women may be related to the fact that they are more careful and concerned regarding their health, seeking medical assistance more frequently. ${ }^{29}$

The mean age of the sample was 59 years old $( \pm 9.6)$, ranging from 40 to 74 years old. This average was close to that found in other studies, evidencing a higher prevalence of tinnitus in individuals around the age of 60 years old. ${ }^{26,27,30}$ It is believed that this finding may be related to possible presbycusis, since it is generally agreed that tinnitus is related to hearing loss, and presbycusis affects individuals as of 60 years of age. ${ }^{31,32}$

Considering tinnitus characteristics, $73.6 \%$ of the participants described the disorder as a wheezing or cricket sound. The predominance of these findings was also observed in other studies, corroborating with the present research. ${ }^{33,34} \mathrm{~A}$ total of $60 \%$ of the participants were bilaterally affected by tinnitus, regardless of loudness. Approximately $26.4 \%$ stated that the symptom was unilateral, and $10.5 \%$ reported occurrence in the head. However, even though in the literature studies also describe a higher prevalence of bilateral tinnitus, ${ }^{29,30,34}$ there is no consensus regarding its location. ${ }^{33}$ Sanches et al suggested that the location of tinnitus could be related to its etiology. ${ }^{35}$

Regarding the duration of tinnitus, $84.2 \%$ of the volunteers reported it as constant, and only $15.8 \%$ considered it variable. This finding was also observed in other researches, thus corroborating with the present study. ${ }^{30,33}$ Concerning loudness, $\sim 50 \%$ of the subjects reported it as moderate, a finding that was also verified in other studies. ${ }^{33,35}$ Cruz observed that the symptom appeared abruptly in $80 \%$ of the partic- ipants. ${ }^{34}$ In the present study, the onset of the disorder occurred practically in a similar way, in which nine patients reported that tinnitus occurred suddenly and progressively. Nonetheless, although result similarity has been evidenced with that found in other studies, in relation to the data regarding the duration of tinnitus, loudness, and the onset of the symptom, it is known that tinnitus is subjective and difficult to characterize, and, therefore, these factors can vary significantly in each individual.

In our sample, $57.9 \%$ of the participants reported discomfort with intense sounds. According to the literature, $~ 40 \%$ of the individuals who have tinnitus exhibit high sensitivity to intense sounds. This result can be explained due to the fact that tinnitus and auditory hypersensitivity have the same pathophysiological basis. ${ }^{36,37}$ Also, an imaging study stated that peripheral hearing loss can generate poor adaptation in the central auditory system, and has, as the primary risk factor, tinnitus and hearing hypersensitivity ${ }^{38}$.

Dizziness was observed in $42.1 \%$ of the participants. This symptom as well as tinnitus may be due to changes in the same structure, the inner ear, and, therefore, often occurring concomitantly. ${ }^{39}$ Headaches and neck pain were the main findings related to the frequently reported pain. Injuries to the neck, middle ear, headaches, and sinusitis increase the risk of tinnitus from 28 to $35 \%{ }^{40}$

Adequate eating habits are essential to maintaining the proper functioning of the inner ear, which practically lacks energy reserves. Thus, in addition to nourishment every 3 hours, it is necessary to lower the consumption of fat and sugar. ${ }^{41,42}$ Approximately $25 \%$ of the individuals stated eating from 1 to 3 meals per day, and $57.9 \%$ reported sweet food ingestion abuse, features that may contribute to the worsening of tinnitus. Therefore, in the present study, food guidelines were given the utmost importance during all of the appointments with the patients, since, even though the extent to which this factor interferes in the worsening of tinnitus is yet unknown, good eating habits may be a determining factor in the improvement of the symptom. Furthermore, in the present study, special attention was given to caffeine intake, given it is known to be a central nervous system stimulant and vasoconstrictor, which may worsen the perception of tinnitus. A study has shown that physicians believe that $50 \%$ of the individuals complaining of tinnitus improve their clinical conditions with reduced caffeine intake. ${ }^{43}$

Regarding previous disease history, head traumas, cardiac disorders, diabetes and high cholesterol, high blood pressure, and migraines were reported; the latter two retaining the highest occurrences in the sample. The possibility of occurrence of these various factors and the probable interaction between them encumbers determining the cause of tinnitus. ${ }^{43}$

Regarding medication use, $52.7 \%$ of the individuals took some type of drug, and $26.3 \%$ reported having used tinnitus relief medication. A recent study stated that pharmacotherapy can trigger or aggravate vestibular symptoms such as vertigo, tinnitus, and dizziness in the elderly, and attention and caution are therefore required in medication prescription in this population. ${ }^{44}$ 
Table 8 Comparison between the results obtained in the different pre- and post-treatment assessments

\begin{tabular}{|c|c|c|c|c|c|c|c|}
\hline & Assessments & & Minimum & Maximum & Average & Standard deviation & $p$-value \\
\hline CAP & $\begin{array}{l}\text { SSW CR } \\
\text { SSW CL } \\
\text { NS RE } \\
\text { NS LE } \\
\text { PPS RE } \\
\text { PPS LE } \\
\text { GIN RE } \\
\text { GIN LE } \\
\text { MLD }\end{array}$ & $\begin{array}{l}\text { Initial } \\
\text { Final } \\
\text { Initial } \\
\text { Final } \\
\text { Initial } \\
\text { Final } \\
\text { Initial } \\
\text { Final } \\
\text { Initial } \\
\text { Final } \\
\text { Initial } \\
\text { Final } \\
\text { Initial } \\
\text { Final } \\
\text { Initial } \\
\text { Final } \\
\text { Initial } \\
\text { Final }\end{array}$ & $\begin{array}{l}57.5 \\
60.0 \\
18.0 \\
17.5 \\
72.0 \\
80.0 \\
76.0 \\
84.0 \\
30.0 \\
73.3 \\
46.6 \\
73.3 \\
5.0 \\
5.0 \\
5.0 \\
5.0 \\
8.0 \\
8.0\end{array}$ & $\begin{array}{l}100 \\
100 \\
98.0 \\
97.5 \\
100 \\
100 \\
100 \\
100 \\
100 \\
100 \\
100 \\
100 \\
15.0 \\
12.0 \\
12.0 \\
10.0 \\
20.0 \\
18.0\end{array}$ & $\begin{array}{l}83.6 \\
85.7 \\
72.8 \\
76.8 \\
91.3 \\
92.6 \\
91.7 \\
93.8 \\
88.5 \\
90.6 \\
89.7 \\
90.6 \\
7.0 \\
7.3 \\
8.2 \\
8.5 \\
13.5 \\
12.9\end{array}$ & $\begin{array}{l}12.4 \\
11.5 \\
23.3 \\
20.6 \\
7.9 \\
6.5 \\
7.3 \\
5.0 \\
16.7 \\
8.7 \\
13.7 \\
8.4 \\
2.8 \\
2.4 \\
1.8 \\
1.8 \\
3.3 \\
2.8\end{array}$ & $\begin{array}{l}0.243 \\
0.061 \\
0.299 \\
0.082 \\
0.592 \\
0.948 \\
0.418 \\
0.626 \\
0.626\end{array}$ \\
\hline THI & $\begin{array}{l}\text { Functional } \\
\text { Emotional } \\
\text { Catastrophic } \\
\text { Total }\end{array}$ & $\begin{array}{l}\text { Initial } \\
\text { Final } \\
\text { Initial } \\
\text { Final } \\
\text { Initial } \\
\text { Final } \\
\text { Initial } \\
\text { Final }\end{array}$ & $\begin{array}{l}0.0 \\
0.0 \\
0.0 \\
0.0 \\
0.0 \\
0.0 \\
8.0 \\
4.0\end{array}$ & $\begin{array}{l}28.0 \\
20.0 \\
30.0 \\
28.0 \\
14.0 \\
14.0 \\
72.0 \\
54.0\end{array}$ & $\begin{array}{l}12.5 \\
7.6 \\
12.6 \\
8.0 \\
6.9 \\
6.5 \\
32.1 \\
21.6\end{array}$ & $\begin{array}{l}8.3 \\
6.5 \\
8.8 \\
6.9 \\
4.3 \\
3.7 \\
19.5 \\
13.7\end{array}$ & $\begin{array}{l}0.044^{*} \\
0.004^{*} \\
0.706 \\
0.023^{*}\end{array}$ \\
\hline VAS & $\begin{array}{l}\text { Initial } \\
\text { Final }\end{array}$ & $\begin{array}{l}2.0 \\
1.0\end{array}$ & $\begin{array}{l}10.0 \\
8.0\end{array}$ & $\begin{array}{l}6.7 \\
4.9\end{array}$ & $\begin{array}{l}2.4 \\
2.1\end{array}$ & $0.001^{*}$ & \\
\hline
\end{tabular}

Abbreviations: CAP, central auditory processing; CR, competitive right; CL, competitive left; RE, right ear; LE, left ear; SSW, staggered spondaic words; NS, noisy speech; PPS, pitch pattern sequence; GIN, gap in noise; MLD, masking level difference; THI, tinnitus handicap inventory; VAS, visual analogical scale; $p$-value, $p$ significance value (Chi-square test).

It was observed that $21.1 \%$ of the participants reported family histories of hearing loss, $31.6 \%$ of tinnitus, and $42.1 \%$ of diabetes. This result corroborates a study from the literature that states that $54.7 \%$ of the subjects with tinnitus complaints have family members with hearing loss, tinnitus or diabetes. ${ }^{43}$

The vast majority of studies with tinnitus patients considered hearing within the normal range when the air thresholds at frequencies between 500 and $8,000 \mathrm{~Hz}$ are $<25 \mathrm{dBHL}^{10,11,45}$ However, in these individuals, it is believed that a significant lesion is present in the external hair cells at frequencies $>8,000 \mathrm{~Hz}$, which may justify the presence of tinnitus. This lesion is detected by high-frequency audiometry, although few establishments have this equipment and, therefore, the evaluation is not conducted. ${ }^{46-48}$ Nevertheless, it is known that hearing loss triggers the occurrence of tinnitus ${ }^{49}$ and, regardless of whether it occurs at the apex or the base of the cochlea, it is believed that individuals who complain of tinnitus have lesions of external hair cells in a specific region of the organ. In the present study, the audiometries were classified according to the Biap ${ }^{21}$ criteria, which considers a greater number of frequencies in the average, from 500 to $4,000 \mathrm{~Hz}$. Thus, 60\% of the sample was composed of subjects who exhibited hearing within the normal standards, bilaterally, which does not corroborate with the findings in the literature due to the previously mentioned reasons.
In acuphenometry, $78.9 \%$ of the volunteers exhibited tinnitus at high frequencies, as of $6,000 \mathrm{~Hz}$. The same result was described in a study that analyzed the frequency and loudness of tinnitus in individuals with presbycusis. However, significant associations between the frequency range of the highest auditory threshold and the frequency of tinnitus were not observed. ${ }^{50}$ Regarding tinnitus loudness, a statistically significant difference was observed in the pre- and postintervention evaluation $(p=0.001)$, evidencing the efficacy of tinnitus habituation therapy in reducing tinnitus loudness.

The existence of a relationship between the loudness of the initial and final tinnitus in acuphenometry and the use of medication was also verified. A statistically significant difference was observed in the group of patients who used 1 to 3 drugs in the final loudness $(p=0.037)$. Of the 6 patients that were part of this group, $50 \%$ exhibited a decrease in tinnitus loudness, and among the others that did not show improvement, 2 maintained the final loudness value and 1 obtained a worsening of $1.0 \mathrm{~dB}$. It is worth mentioning that the latter had already used medication for tinnitus relief. The pharmacological groups that these patients were exposed to were not described, although it is believed that the use of drugs can contribute to generating resistance in reducing the loudness of tinnitus. ${ }^{44}$

Regarding auditory hypersensitivity, the values of the preand post-treatment discomfort threshold were compared, 
and a statistically significant difference was not observed in both ears $(p=0.416$ and 0.287 in the right and left ears, respectively). However, there was an increase in the number of participants who had negative discomfort thresholds in both ears, that is, they did not exhibit auditory hypersensitivity after treatment. We believe that statistical significance was not achieved due to the small size of the sample. Nonetheless, a post-treatment trend of reduction in the number of patients classified as displaying severe discomfort thresholds was observed, in addition to an increase in the number of individuals with negative discomfort thresholds, indicating a decrease in the absolute number of individuals with auditory hypersensitivity.

Regarding the auditory processing evaluation, a statistically significant difference was not observed in the pre- and posttreatment evaluation. Although the reduction in the perception of the individual on the loudness and annoyance of tinnitus was verified, as well as the improvement of the impact of this symptom on the quality of life of the participant, the influence of these factors in the development of auditory processing abilities was not observed. The comparison of the auditory processing test results among normal hearing patients and those with hearing loss showed a statistically significant influence $(p=0.045)$ regarding the SSW test in the right competitive condition. This condition is known to be directly related to changes in the left hemisphere, which is dominant for language. Therefore, even mild hearing loss may influence the linguistic aspects of the patient. ${ }^{51}$

In the comparison between the initial and final THI, a statistically significant difference was observed regarding the functional, emotional, and total aspects. Statistical significance was not achieved regarding the catastrophic aspect. As for VAS, a statistically significant difference was also observed in the comparison between the initial and final values. These results demonstrate a reduction in the impact of tinnitus on the quality of life of the patient and the discomfort caused by the symptom. It is believed that guideline emphasis, as well as follow-ups of patients through frequent appointments, was of fundamental importance in their progress, contributing to the strengthening of the therapist-patient bond, which consequently generates more confidence in the proposed treatment, and facilitates patient acceptance in relation to the changes in attitude required to improve tinnitus.

Finally, due to the small sample size of the present study, we need more data to find the generalizability of our results. The present study is indeed a preliminary step to move toward a comprehension on the influence of tinnitus therapy on auditory abilities. Further investigation in a larger sample of tinnitus patients is therefore warranted, along with an exploration of the impact tinnitus may have on the auditory processing skills.

\section{Conclusion}

Tinnitus habituation therapy was effective in reducing the perception of tinnitus loudness and discomfort, as well as the impact of the symptom on the quality of life of the patient.
However, the influence of these factors on the improvement of auditory processing skills was not observed.

Conflict of Interests

The authors have no conflict of interests to declare.

\section{References}

1 Jafaria Z, Toufan R, Aghamollaei M, Asad Malayeri S, Rahimzadeh S, Esmaili M. Imapct of tinnitus on divided and selective auditory attention in workers expose to occupational noise. Advances in cognitive. Science 2012;14(03):51-62

2 Okada DM, Onishi ET, Chami FL, Borin A, Cassola N, Guerreiro VM. O uso da acupuntura para alívio imediato do zumbido. Rev Bras Otorrinolaringol 2006;72(02):182-186

3 Lasisi AO, Abiona T, Gureje O. Tinnitus in the elderly: Profile, correlates, and impact in the Nigerian Study of Ageing. Otolaryngol Head Neck Surg 2010;143(04):510-515

4 Pinto PCL, Sanchez TG, Tomita S. Avaliação da relação entre severidade do zumbido e perda auditiva, sexo e idade do paciente. Rev Bras Otorrinolaringol (Engl Ed) 2010;76(01):18-24

5 Baguley DM. Hyperacusis. J R Soc Med 2003;96(12):582-585

6 Lewis JE, Stephens SD, McKenna L. Tinnitus and suicide. Clin Otolaryngol Allied Sci 1994;19(01):50-54

7 Langers DRM, de Kleine E, van Dijk P. Tinnitus does not require macroscopic tonotopic map reorganization. Front Syst Neurosci 2012;6(02):2

8 Huang CY, Lee HH, Chung KC, Chen HC, Shen YJ, Wu JL. Relationships among speech perception, self-rated tinnitus loudness and disability in tinnitus patients with normal pure-tone thresholds of hearing. ORL J Otorhinolaryngol Relat Spec 2007;69(01):25-29

9 Newman CW, Wharton JA, Shivapuja BG, Jacobson GP. Relationships among psychoacoustic judgments, speech understanding ability and self-perceived handicap in tinnitus subjects. Audiology 1994;33(01):47-60

10 Branco-Barreiro FCA. Zumbido em adultos ouvintes normais: um estudo sobre o processamento auditivo central e o handicap [Thesis]. São Paulo (SP): Pontifícia Universidade Católica de São Paulo; 1998

11 Ryu IS, Ahn JH, Lim HW, Joo KY, Chung JW. Evaluation of masking effects on speech perception in patients with unilateral chronic tinnitus using the hearing in noise test. Otol Neurotol 2012;33 (09):1472-1476

12 Esteves CC, Brandão FN, Siqueira CGA, Carvalho SAS. Audição, zumbido e qualidade de vida: um estudo piloto. Rev CEFAC 2012; 14(05):836-843

13 Martins ML, et al. Interferência do zumbido no reconhecimento e percepção de fala. Anais do XXIII Congresso Brasileiro e IXCongresso Internacional de Fonoaudiologia. Salvador/BA, Brazil, 2015

14 Azevedo A, Figueiredo R. Atualização em zumbido. Rev Bras Otorrinolaringol 2004;70(01):27-40

15 Jastreboff PJ. Phantom auditory perception (tinnitus): mechanisms of generation and perception. Neurosci Res 1990;8(04):221-254

16 Grewal R, Spielmann PM, Jones SE, Hussain SS. Clinical efficacy of tinnitus retraining therapy and cognitive behavioural therapy in the treatment of subjective tinnitus: a systematic review. J Laryngol Otol 2014;128(12):1028-1033

17 Branco-Barreiro FCA, Knobel KAB, Sanches TG. Modelo neurofisiológico do zumbido. In: Samelli AG. Zumbido: avaliação, diagnóstico e reabilitação. São Paulo: Louvise; 2004:87-93

18 Sanches TG, Pedalini MEB, Bento RF. Aplicação da terapia de retreinamento do zumbido (TRT) em hospital público. Arq Int Otorrinolaringol 2002;6(01):29-38

19 Tyler RS, Noble W, Coelho CB, Ji H. Tinnitus retraining therapy: mixing point and total masking are equally effective. Ear Hear 2012;33(05):588-594 
20 Standardisation Of II. ISO 8253-1, Acoustics-Audiometric test methods - Part 1: Basic pure tone air and bone conduction threshold audiometry. Geneva: ISO; 1989

21 International Bureau for Audiophonology Rec_02-1_en Page 1 of 2 BIAP Recommendation 02/1: Audiometric Classification of Hearing Impairments http://www.biap.org/es/recommandations/recommendations/tc-02-classification/213-rec-02-1-en-audiometric-classification-of-hearing-impairments/file. Accessed on March 17, 2020

22 Jerger J. Clinical experience with impedance audiometry. Arch Otolaryngol 1970;92(04):311-324

23 Goldstein B, Shulman A. Tinnitus, hyperacusis and loudness discomfort level test: a preliminary report. Int Tinnitus J 1996; 2(01):83-89

24 Axelsson A, Ringdahl A. Tinnitus-a study of its prevalence and characteristics. Br J Audiol 1989;23(01):53-62

25 Meikle MB, Vernon J, Johnson RM. The perceived severity of tinnitus. Some observations concerning a large population of tinnitus clinic patients. Otolaryngol Head Neck Surg 1984;92(06):689-696

26 Mondelli MFCG, Rocha AB. Correlação entre os achados audiológicos e incômodo com zumbido. Arq Int Otorrinolaringol 2011; 15(02):172-180

27 Pinto PCL, Sanches TG, Tomita S. Avaliação da relação entre severidade do zumbido e perda auditiva, sexo e idade do paciente. Braz J Otorrinolaryngol 2010;76(01):18-24

28 Stouffer JL, Tyler RS. Characterization of tinnitus by tinnitus patients. J Speech Hear Disord 1990;55(03):439-453

29 Coelho CCB, Sanchez TG, Bento RF. Características do zumbido em pacientes atendidos em serviço de referência. Arq Int Otorrinolaringol 2004;8(03):284-292

30 Pinto PCL, Hoshino AC, Tomita S. Características do pacientes com queixa de zumbido atendidos em ambulatório especializadoHUCFF. Cad Saude Colet 2008;16(03):437-448

31 Sanchez TG, Medeiros IRT, Levy CPD, Ramalho JRO, Bento RF.Zumbido em pacientes com audiometria normal: caracterização clínica e repercussões. Rev Bras Otorrinolaringol 2005;71(04):427-431

32 Lessa AH, Hennig TR, Costa MC, Rossi AG. Resultados da reabilitação auditiva em idosos usuários de próteses auditivas avaliados com teste dicótico. CoDAS 2013;25(02):169-175

33 Steinmetz LG, Zeigelboim BS, Lacerda AB, Morata TC, Marques JM. Caracteristicas do zumbido em trabalhadores expostos a ruído. Rev Bras Otorrinolaringol 2009;75(01):7-14

34 Cruz AP. Estimulação magnética transcraniana no tratamento do zumbido [Tese]. Campina Grande (PB): Universidade Estadual da Paraíba; 2014

35 Sanches TG, Bento RF, Miniti A, Câmara J. Zumbido: características e epidemiologia. Experiência do hospital das clínicas da Facul- dade de Medicina da Universidade Federal de São Paulo. Braz J Otorrinolaryngol 1997;63(03):229-235

36 Sanchez TG, Pedalini MEB, Bento RF. Hiperacusia: artigo de revisão. Arquivos Fundação Otorrinolaringol 1999;3(04):184-188

37 Bassanelo A. Estudo da hiperacusia: revisão bibliográfica [Monography]. São Paulo (SP): CEFAC; 2000

38 Mühlnickel W, Elbert T, Taub E, Flor H. Reorganization of auditory cortex in tinnitus. Proc Natl Acad Sci U S A 1998;95(17): 10340-10343

39 Almeida LD, Mitre EI, Lemos L, Simões ECC. Vestibulometria em indivíduos com zumbido e exame audiológico normal. CEFAC 2005;7(03):382-387

40 Sindhusake D, Golding M, Newall P, Rubin G, Jakobsen K, Mitchell P. Risk factors for tinnitus in a population of older adults: the blue mountains hearing study. Ear Hear 2003;24(06):501-507

41 Sanches TG, Medeiros IRT, Coelho FF, Constantino GTL, Bento RF Frequência de alterações da glicose, lipídeos e hormônios tireoidianos em pacientes com zumbido. Arq Int Otorrinolaringol 2001;5(01):6-10

42 Almeida TAS, Samelli AG, Mecca FDN, Martino E, Paulino AM Sensação subjetiva do zumbido pré e pós-intervenção nutricional. Pro Fono 2009;21(04):291-296

43 Weber SR, Périco E. Zumbido no trabalhador exposto ao ruído. Rev Soc Bras Fonoaudiol 2011;16(04):459-465

44 Paulino CA, Benedito JS. Uso de medicamentos entre pacientes idosos vestibulopatas. Rev Equil Corporal Saúde 2011;3(02):10-22

45 Acrani IO, Pereira LD. Resolução temporal e atenção seletiva de indivíduos com zumbido. Pro Fono 2010;22(03):233-238

46 Corona AP, Figuerêdo RBS. Influência do zumbido nos limiares auditivos de altas frequências. Rev Soc Bras Fonoaudiol 2007;12 (01):29-33

47 Burguetti FAR, Peloggia AG, Carvallo RMM. Limiares de audibilidade em altas frequências em indivíduos com queixa de zumbido. Arq Int Otorrinolaringol 2004;8(04):277-283

48 Klagenberg KF, Oliva FC, Gonçalves CGO, Lacerda ABM, Garofani VG, Zeigelboim BS. Audiometria de altas frequências no diagnóstico complementar em audiologia: uma revisão da literatura nacional. Rev Soc Bras Fonoaudiol 2011;16(01): 109-114

49 Auerbach BD, Rodrigues PV, Salvi RJ. Central gain control in tinnitus and hyperacusis. Front Neurol 2014;5:206

50 Seimetz BM, Teixeira AR, Rosito LPS, Flores LS, Pappen $\mathrm{CH}$, Dalligna C. Análise do pitch e loudness do zumbido em indivíduos com presbiacusia. Clin Biomed Res 2014:34

51 Araújo NSS, Ruiz ACP, Pereira LD. SSW- Análise quantitativa dos erros: inventário de atendimento de 2005. Rev CEFAC 2009;11(01): 